\title{
Neutrophil-to-Lymphocyte Ratio as a Prognostic Indicator in Patients With Unresectable Gastric Cancer
}

\author{
YUKI MURAKAMI*, HIROAKI SAITO*, SHOTA SHIMIZU, YUSUKE KONO, YUJI SHISHIDO, \\ KOZO MIYATANI, TOMOYUKI MATSUNAGA, YOJI FUKUMOTO and YOSHIYUKI FUJIWARA \\ Division of Surgical Oncology, Department of Surgery, School of Medicine, \\ Tottori University Faculty of Medicine, Yonago, Japan
}

\begin{abstract}
Background/Aim: Although many prognostic indicators have been identified for resectable gastric cancer $(G C)$, prognostic indicators for unresectable GC (urGC) have not been widely studied. The aim of the current study was to investigate prognostic indicators that could be determined through routine blood examinations in patients with urGC. Patients and Methods: We retrospectively analyzed clinicopathological factors in 92 patients with unresectable advanced and recurrent gastric adenocarcinoma. Results: Based on receiver operating curve analysis, neutrophil-to-lymphocyte ratio (NLR) had the highest area under curve for 1-year survival among patients with urGC. Among patients with urGC, NLR was significantly higher in those with advanced disease compared to those with recurrent disease $(p=0.0051)$; and in those with peritoneal metastasis compared to those without peritoneal metastasis $(p=0.041)$. Patients were divided into $N L R^{H i g h}(N L R \geq 2.83)$ and $N L R^{\text {Low }}(N L R<2.83)$. Their median survival times were NLR High 9.1 months and $N L R^{\text {Low }}$ : 17.1 months $(p<0.0001)$. NLR was also inversely correlated with survival period $(r=0.496, p<0.0001)$; and NLR measured one month after starting chemotherapy was significantly associated with the prognosis of both $N L R^{\text {Low }}$ and NLR High patients with urGC. Multivariate analysis showed NLR to be an independent predictor of overall survival in these patients. Conclusion: NLR is useful for predicting the prognosis of patients with unresectable GC. An estimated 1,300,000 new cases of gastric cancer (GC)
\end{abstract}

*These Authors contributed equally to this work.

Correspondence to: Hiroaki Saito, Division of Surgical Oncology, Department of Surgery, School of Medicine, Tottori University Faculty of Medicine, 36-1 Nishi-cho, Yonago 683-8504, Japan. Tel: +81 859386567, Fax: +81 859386569, e-mail: sai10@tottori-u.ac.jp

Key Words: Gastric cancer, NLR, prognosis, recurrence. and 819,000 deaths from GC occurred in 2015 worldwide, ranking GC the fifth most commonly diagnosed cancer and the third most common cause of death from cancer $(1,2)$.

Gastrectomy with regional lymph node dissection is the mainstay of curative GC treatment. However, many GC patients experience recurrence even after complete tumor removal (R0 resection) (3). Furthermore, some patients present with unresectable advanced gastric cancer at the time of diagnosis. The Japanese Gastric Cancer Treatment Guideline recommends chemotherapy (CT) for patients with unresectable GC (urGC) (4). Although advances in CT have improved prognosis of urGC patients, their median survival is still only 1 year $(5,6)$. In addition, CT is associated with various adverse events. Therefore, accurate prognostic indicators for urGC patients are necessary to determine optimal treatment strategies and to provide patients with important information concerning their outcome.

Markers that reflect inflammation and nutritional status, many of which can be determined through routine blood examinations, have been associated with the prognosis of cancer patients. For instance, peripheral neutrophil count and serum $\mathrm{C}$ reactive protein (CRP) level reflect inflammation, whereas serum albumin level and peripheral lymphocyte count (LC) reflect nutritional status. Some evaluation scores have been developed that combine inflammation-related and nutrition-related markers, such as the neutrophil-tolymphocyte ratio (NLR) and prognostic nutritional index (PNI), both of which have been shown to predict prognosis in patients with $\mathrm{GC}(7,8)$.

However, studies of prognostic indices in GC have been performed mainly for patients who have undergone surgery. Migita et al., recently demonstrated that inflammation-based scores, including NLR and PNI, are also convenient prognostic predictors of survival times for patients with recurrent GC (9), however, prognostic indicators for urGC patients have not been widely studied thus far. The aim of the current study was to investigate prognostic indicators in patients with urGC. 


\section{Patients and Methods}

This study was a retrospective analysis of 92 patients with unresectable advanced and recurrent gastric adenocarcinoma, who were treated at our institution between January 2006 and September 2017. The clinicopathologic findings were determined according to the Japanese Classification of Gastric Carcinoma (10).

Following the diagnosis of recurrence and unresectable advanced GC, all patients underwent CT. Their CT regimens included: i) S-1 $(n=13)$, ii) paclitaxel $(n=3)$, iii) docetaxel $(n=1)$, iv) CPT-11 $(n=13), v)$ combined S-1 + cisplatin ( $\mathrm{n}=25)$, vi) combined CPT-11 + cisplatin $(\mathrm{n}=3)$, vii) combined $\mathrm{S}-1+$ docetaxel $(\mathrm{n}=12)$, viii) combined paclitaxel + ramucirumab $(n=6)$, ix $)$ combined S-1 + CPT- $11(n=1), x)$ combined $\mathrm{S}-1+$ trastuzumab $(\mathrm{n}=1)$, xi) combined $\mathrm{S}-1+$ oxaliplatin $(\mathrm{n}=3)$, xii) combined capecitabine + cisplatin $(n=1)$, xiii) combined capecitabine + oxaliplatin $(n=2)$, xiv) combined capecitabine + trastuzumab $(n=2)$, $\mathrm{xv})$ combined capecitabine + cisplatin + trastuzumab $(\mathrm{n}=1)$, $\mathrm{xvi})$ combined capecitabine + oxaliplatin + trastuzumab $(n=1)$, xvii $)$ combined docetaxel + cisplatin $+\mathrm{S}-1(\mathrm{n}=2)$, xviii) combined $\mathrm{S}-1+5-$ $\mathrm{FU}+$ liver-infused mitomycin-C $(\mathrm{n}=1)$ and $\mathrm{xix})$ combined $\mathrm{S}-1+$ paclitaxel + intraperitoneally infused paclitaxel $(n=1)$. Of the 92 patients who underwent $\mathrm{CT}$ for urGC, 33 (35.9\%) received second-line CT, including paclitaxel $(n=7)$, docetaxel $(n=1)$, nab-paclitaxel $(n=8)$, CPT-11 ( $n=9)$, combined S-1 + docetaxel $(n=1)$, combined paclitaxel + ramucirumab $(n=6)$, and combined capecitabine + cisplatin + trastuzumab $(n=1)$. Ten patients received neoadjuvant chemotherapy before gastrectomy: i) combined S-1 + cisplatin $(n=9)$ and ii) combined docetaxel + cisplatin $+S-1(n=1)$ and 46 patients received adjuvant chemotherapy after gastrectomy: i) S-1 $(n=43)$, ii) combined $S-1+$ cisplatin $(n=2)$ and iii) combined cisplatin + docetaxel $(n=1)$.

Causes of death and patterns of recurrence were determined by reviewing medical records, including laboratory data, ultrasonography, computed tomography, scintigrams, peritoneal punctures and laparotomies, or by direct inquiry of family members.

Serum concentrations of CRP, albumin and carcinoembryonic antigen (CEA), and numbers of peripheral neutrophils, lymphocytes, and platelets at the time of diagnosis of urGC were obtained from patients' records. The NLR was obtained by dividing the peripheral neutrophil count (NC) by the peripheral LC. The PLR was obtained by dividing the peripheral thrombocyte count by the peripheral lymphocyte count. The platelet $\times$ CRP multiplier value (P-CRP) was defined based on the product of the peripheral thrombocyte count $\times$ the serum CRP level divided by $10^{4}$. PNI was calculated by $10 \times \mathrm{Alb}+0.005 \times \mathrm{TLC}$. The CRPto-albumin ratio was obtained by dividing the serum concentration of CRP by the serum albumin level. With regard to modified Glasgow Prognostic Score (mGPS), patients with elevated C-reactive protein levels $(>0.5 \mathrm{mg} / \mathrm{dL})$ and hypoalbuminemia $(<3.5 \mathrm{~g} / \mathrm{dL})$ were assigned mGPS of 2 , those with one abnormality in either parameter were assigned mGPS of 1 , and those with neither abnormality were assigned mGPS of 0 .

The Institutional Review Board of our institution approved of this study. The informed consent requirement was waived. All procedures performed in studies with human participants were in accordance with the ethical standards of the Institutional Research Committee and with the 1964 Helsinki Declaration and its later amendments or with comparable ethical standards. The authors have no conflicting financial interests.

Statistical analysis. Differences between the two groups were evaluated using the Mann-Whitney $U$-test. Correlation between
NLR and survival period was analyzed using the Spearman rank correlation coefficient. The Youden index was calculated using receiver operating characteristic (ROC) analysis to determine optimal cutoffs for the NLR in the survival analysis. Survival curves were calculated according to the Kaplan-Meier method. Differences between the curves were identified using the log-rank test. Multivariate analyses of factors considered as prognostic of overall survival (OS) were performed together with Cox's proportional hazards model and a stepwise procedure. $p<0.05$ was considered significant. GraphPad Prism (GraphPad Software, Inc., La Jolla, CA, USA) and Stat View (Abacus Concepts, Inc., Berkeley, CA, USA) software packages were used for the statistical analyses.

\section{Results}

The median survival time (MST) of patients in this study was 13.5 months. Figure 1 shows the area under curve (AUC) of each examined prognostic indicator by ROC analysis for 1year OS. Among those indicators, NLR had the highest AUC, i.e., the highest predictive value. Table I shows correlations between clinicopathologic factors and NLR in patients with urGC. Among patients with urGC, NLR was significantly higher in those with advanced disease compared to those with recurrent disease $(p=0.0051)$, and in those with peritoneal metastasis compared to those without peritoneal metastasis $(p=0.041)$. ROC analysis showed the optimal cut-off value of NLR is 2.83 (AUC $=0.782, p<0.0001$ ). Based on this cutoff value, patients were divided into $\mathrm{NLR}^{\mathrm{High}}(\mathrm{NLR} \geq 2.83, \mathrm{n}=44)$ and $\mathrm{NLR}^{\text {Low }}(\mathrm{NLR}<2.83, \mathrm{n}=48)$. Their MSTs were $\mathrm{NLR}^{\text {High }}=9.1$ months and NLR ${ }^{\text {Low }}=17.1$ months $(p<0.0001$, Figure 2). NLR and survival period were inversely correlated $(\mathrm{r}=-0.496, p<0.0001$, Figure 3$)$. It is likely that the transition rate to second-line $\mathrm{CT}$ might be associated with survival. The rates of transition to second-line CT were $77.1 \%$ and 59.1 in $\mathrm{NLR}^{\mathrm{Low}}$ and $\mathrm{NLR}^{\mathrm{High}}$, respectively, and the difference tended to be significant $(p=0.064)$. Furthermore, patients who received second-line $\mathrm{CT}$ had a significantly longer median survival (14.5 months) compared to those who did not receive second-line CT (10.5 months, $p=0.011)$.

Multivariate analysis (using Cox's proportional hazards model and a stepwise procedure) of sex, age, number of incurable factors, number of chemotherapy line, presence of peritoneal metastasis, hematogenous metastasis, and/or lymphnode metastasis, either non-resectable advanced GC or recurrent GC, neutrophil count, platelet count, serum albumin level, serum CRP ratio, PNI, CRP to albumin level, PNI, P-CRP, and NLR, indicated that only NLR was an independent prognostic indicator for OS (hazard ratio=1.116, 95\% Confidence Interval $=1.063-1.171, p<0.0001)$.

We determined patients' NLRs 1 month after starting chemotherapy, and divided them into post-NLR ${ }^{\text {High }}(\geq 2.83)$ and post-NLR ${ }^{\text {Low }}(<2.83)$. Among the 48 patients initially in the NLR ${ }^{\text {Low }}$ group, i.e., at diagnosis, 5 patients had shifted to post-NLR ${ }^{\text {High }}$, and 43 patients were post-NLR ${ }^{\text {Low }}$. Among 


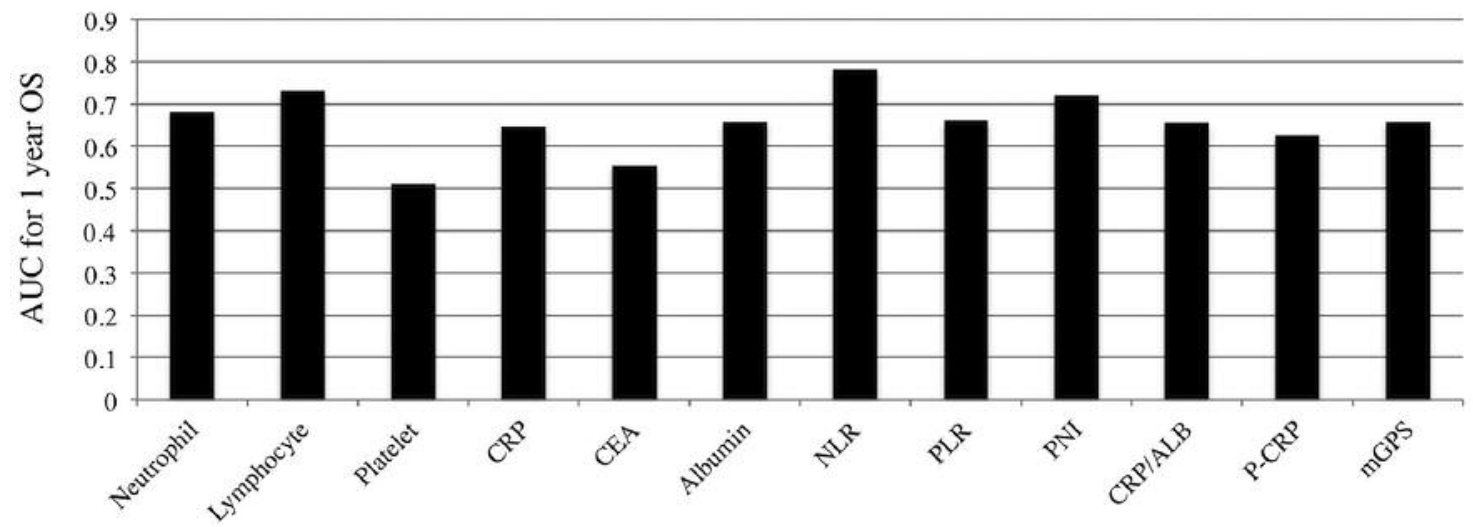

Figure 1. Area under curve for each examined factor for 1-year overall survival by receiver operating characteristic analysis in patients with unresectable gastric cancer. AUC: Area under curve; OS: overal survival.

the patients who were $\mathrm{NLR}^{\mathrm{Low}}$ at diagnosis, prognosis of post-NLR ${ }^{\text {High }}$ patients was significantly worse compared to post-NLR ${ }^{\text {Low }}$ patients ( $p=0.048$, Figure $\left.4 \mathrm{~A}\right)$. Among the 44 patients in the NLR ${ }^{\text {High }}$ group at diagnosis, 21 shifted to post$\mathrm{NLR}^{\text {Low }}$ and 23 were post-NLR ${ }^{\text {High }}$, and their post-NLR ${ }^{\text {High }}$ subgroup also had a significantly worse prognosis compared to their post-NLR ${ }^{\text {Low }}$ subgroup ( $p=0.0095$, Figure 4B).

\section{Discussion}

Outcomes of patients with cancer are determined by both tumor-related and patient-related factors. In GC, depth of invasion and lymph node metastasis are the most important tumor-related prognostic factors $(11,12)$, whereas inflammation, malnutrition, and immune status are relevant patient-related factors. In this study, we determined the prognostic significance of serum parameters that could be obtained from blood tests, including NC, LC, PC, serum concentration of CRP, albumin, NLR, PLR, PNI, CRP/alb, $\mathrm{P}-\mathrm{CRP}$, and mGPS as patient-related factors, and CEA as a tumor-related factor, in urGC patients. Among these indicators, NLR had the most predictive value for urGC patients in the current study.

The reason behind poor prognosis in patients with high NLR remains unclear, although it is likely related to the respective functions of neutrophils and lymphocytes. High NLR reflects an elevated peripheral neutrophil count Neutrophils are important components of the inflammatory response, which has dual roles in tumor development and metastasis. In response to cytokine stimulation, neutrophils can diverge towards antitumor (N1) or protumor (N2) phenotypes (13). In the acute inflammation state, neutrophils are activated to exert an antitumor effect (13). Conversely, neutrophils activated by chronic inflammation can promote tumor growth and metastasis. Inflammatory cytokines such
Table I. Relationship between NLR and clinicopathological variables in patients with unresectable advanced and recurrent gastric cancers.

\begin{tabular}{|c|c|c|}
\hline Variable & NLR & $p$-Value \\
\hline Unresectable cause & & 0.0051 \\
\hline Advanced cases $(n=36)$ & $4.39 \pm 4.77$ & \\
\hline Recurrent cases $(n=56)$ & $2.81 \pm 2.12$ & \\
\hline Gender & & 0.12 \\
\hline Male $(n=73)$ & $3.4 \pm 3.82$ & \\
\hline Female $(n=19)$ & $3.53 \pm 1.72$ & \\
\hline Age & & 0.44 \\
\hline$<75(\mathrm{n}=69)$ & $3.45 \pm 3.85$ & \\
\hline$\geq 75(n=23)$ & $3.36 \pm 2.13$ & \\
\hline Peritoneal metastases & & 0.041 \\
\hline Present $(n=44)$ & $3.69 \pm 2.6$ & \\
\hline Absent $(n=48)$ & $3.18 \pm 4.15$ & \\
\hline Hematogenous metastases & & 0.55 \\
\hline Present $(n=34)$ & $3.99 \pm 4.87$ & \\
\hline Absent $(n=58)$ & $3.09 \pm 2.31$ & \\
\hline Lymph node metastases & & 0.59 \\
\hline Absent $(n=36)$ & $3.6 \pm 4.69$ & \\
\hline Present $(n=56)$ & $3.32 \pm 2.47$ & \\
\hline Number of metastases & & 0.068 \\
\hline One $(n=72)$ & $3.01 \pm 2.27$ & \\
\hline Two and more $(\mathrm{n}=20)$ & $4.93 \pm 6.0$ & \\
\hline Number of chemotherapy line & & 0.068 \\
\hline One $(\mathrm{n}=29)$ & $3.88 \pm 2.84$ & \\
\hline Two and more $(\mathrm{n}=63)$ & $3.21 \pm 3.75$ & \\
\hline
\end{tabular}

All results are expressed as mean \pm SD.

as G-CSF, IL-6, and TGF- $\beta 1$ can induce the N2 phenotype of neutrophils in bone marrow and tumor microenvironment (14). In addition, priming with IFN- $\gamma$ and TNF- $\alpha$ can convert the phenotype from N2 to N1 (15). Neutrophils may, thus, exert either antitumoral or protumoral functions, depending on the mediating inflammatory cytokines. We have 

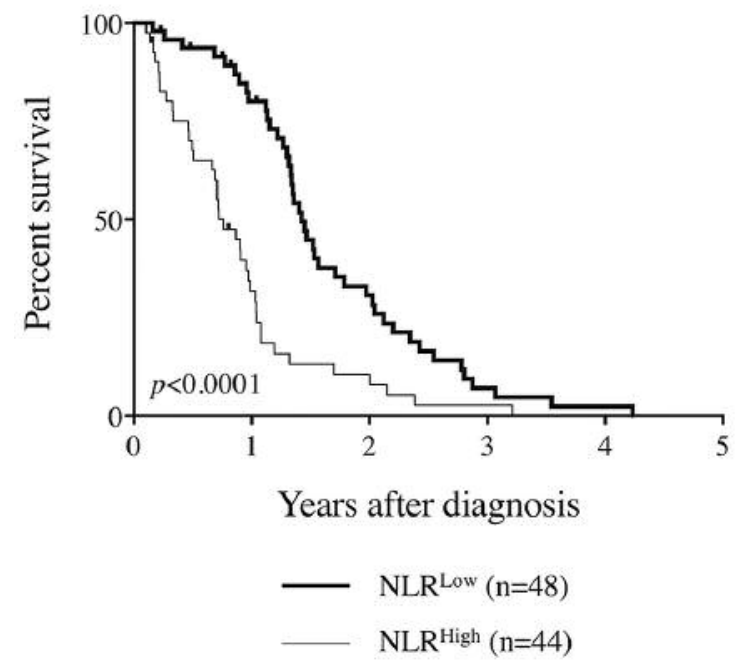

Figure 2. Overall survival curves by neutrophil-to-lymphocyte ratio in patients with unresectable gastric cancer.

previously reported that elevated serum IL-6 concentration can be observed in GC patients (16). Therefore, most of the increased numbers of neutrophils observed in patients with unresectable advanced and recurrent GC are probably of the N2 phenotype, which exert a protumoral effect. This could explain the close correlation between elevated NC and the poor prognosis of patients with unresectable advanced and recurrent GC in the current study.

High NLR also reflects a decreased LC. Several other studies have also shown that low preoperative LC is related to poor prognosis in various cancers, including pancreatic cancer (17), esophageal cancer (18), renal cancer (19), and sarcoma and lymphoma (20). Lymphocytes include $\mathrm{CD}^{+}$and $\mathrm{CD}^{+} \mathrm{T}$ cells, NK cells, NKT cells, gamma-delta T cells, and B cells, which are closely associated with tumor immunity. Therefore, the presence of low numbers of those cells is probably associated with impaired tumor immunity, which in turn results in tumor progression. In fact, several studies have shown that low numbers of tumor-infiltrating lymphocytes, such as $\mathrm{CD}^{+}$and $\mathrm{CD}^{+} \mathrm{T}$ cells, are associated with poor prognosis in some cancers (21-23). Furthermore, low numbers of immune cells, such as NK cells, B cells, and gamma-delta T cell have been associated with poor prognosis in both peripheral blood and cancer tissue for some cancer types (24-26). Therefore, peripheral LC might be a good indicator of cell-mediated immune status, including both acquired and adaptive immunity, and humoral immune status against GC.

A high transition rate to second-line CT might be associated with longer survival. In patients treated with palliative CT, second-line or subsequent CT had greater effects on survival time. In fact, we observed that patients who received second-line CT had a significantly longer

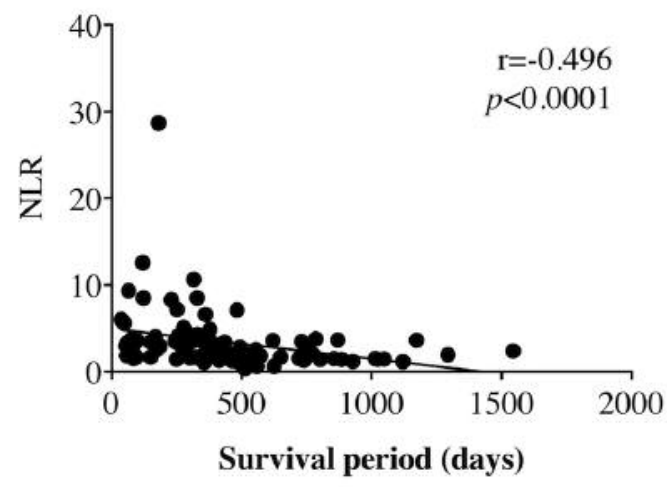

Figure 3. Correlation between survival period and neutrophil-to-lymphocyte ratio in patients with unresectable gastric cancer.

median survival compared to those who did not receive second-line CT. The rate of transition to second-line CT among low-NLR patients with unresectable recurrent GC cancer was reported to be significantly higher compared to high-NLR patients (9). This suggests that patients with low NLR could continue with second- or third-line treatments should they have adequate physical reserves. In the current study, the rate of transition to second-line CT in the lowNLR group also tended to be significantly higher compared to the high-NLR group. Therefore, high rate of transition to second-line CT would likely be associated with favorable prognosis in low-NLR patients with urGC.

Knowing if CT is efficacious as soon as possible after its introduction is extremely important. In the current study, therefore, we determined NLR one month after initiating CT and found that post-NLR was significantly associated with prognosis in both the NLR ${ }^{\text {High }}$ and NLR ${ }^{\text {Low }}$ groups, which implies that post-NLR can be used to assess CT efficacy.

Recently, nivolumab, the antibody to programmed cell death protein 1 , was shown to be effective in the treatment of urGC (27). Svaton et al. has demonstrated that a laboratory panel reflecting chronic inflammation including NLR was a potential predictive marker of nivolumab treatment in patients with advanced non-small cell lung cancer (28). Therefore, NLR also might be a potential predictive marker of nivolumab treatment in patients with urGC. Further investigations are urgently required to determine the correlation between NLR and the efficacy of nivolumab treatment in patients with urGC.

Our study had a few limitations. First, since it was retrospective it was subjected to a bias. Second, we enrolled patients with both recurrent urGC and advanced urGC. However, NLR was significantly higher in patients with advanced disease compared to those with recurrent disease, which indicates that the prognostic significance of NLR might differ between these two disease aspects. Third, we 
a

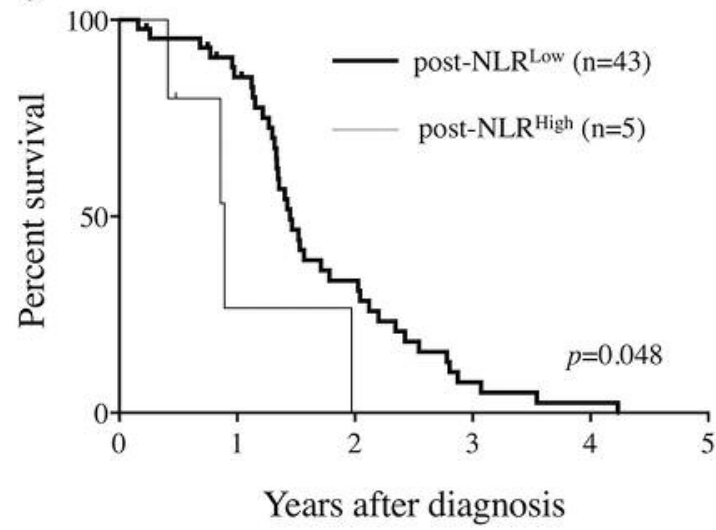

b

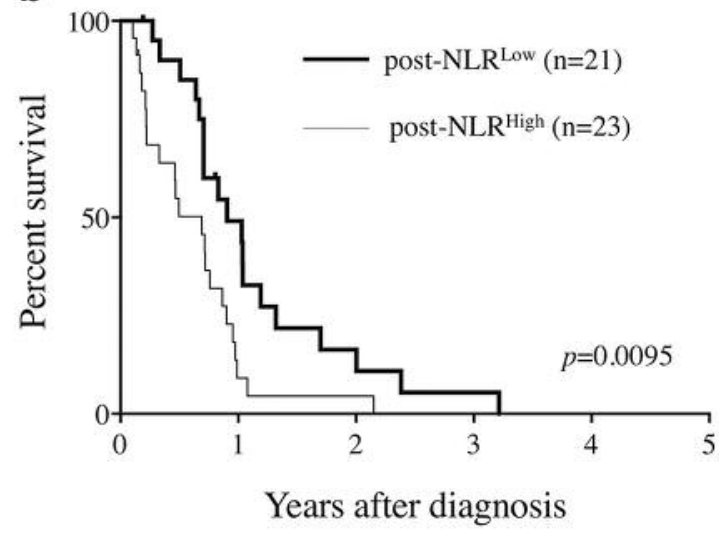

Figure 4. Correlations between survival period and neutrophil-to-lymphocyte ratio (NLR) measured 1 month after starting chemotherapy in patients with unresectable gastric cancer and previously found to have either: (A) NLR Low (<2.83) or (B) NLRHigh ( $\geq 2.83)$ at diagnosis.

determined the prognostic significance of NLR at the time of diagnosis of urGC in the current study, however, it is not clear whether this is the optimal timing to measure NLR. Fourth, the number of patients included in our study was small and the results must, therefore, be confirmed in a large-scale, prospective, randomized, controlled trial.

In conclusion, our study shows the potential utility of NLR at the time of diagnosis of urGC to predict the prognosis in patients with urGC. Because these serum markers are convenient and inexpensive to measure, NLR could be especially useful in routine clinical settings.

\section{Conflicts of Interests}

The Authors have no conflicts of interest.

\section{Authors' Contributions}

The study conception and design were performed by HS, the acquisition of data by YM, SS, YK, YS, KM, TM, and YF. The analysis and interpretation of data were performed by $\mathrm{YM}$ and HS, the drafting of the manuscript by YM and HS and the critical revision by YF. All authors approved the final version of the article.

\section{Acknowledgements}

The Authors would like to thank Liwen Bianji, Edanz Group China (www.liwenbianji.cn/ac), for editing the English text of a draft of this manuscript.

\section{References}

1 Forman D and Burley VJ: Gastric cancer: Global pattern of the disease and an overview of environmental risk factors. Best practice \& research. Clin Gastroenterol 20: 633-649, 2006. PMID: 16997150. DOI: 10.1016/j.bpg.2006.04.008
2 Fitzmaurice C, Allen C, Barber RM, Barregard L, Bhutta ZA, Brenner H, Dicker DJ, Chimed-Orchir O, Dandona R, Dandona L, Fleming T, Forouzanfar MH, Hancock J, Hay RJ, HunterMerrill R, Huynh C, Hosgood HD, Johnson CO, Jonas JB, Khubchandani J, Kumar GA, Kutz M, Lan Q, Larson HJ, Liang X, Lim SS, Lopez AD, MacIntyre MF, Marczak L, Marquez N, Mokdad AH, Pinho C, Pourmalek F, Salomon JA, Sanabria JR, Sandar L, Sartorius B, Schwartz SM, Shackelford KA, Shibuya K, Stanaway J, Steiner C, Sun J, Takahashi K, Vollset SE, Vos T, Wagner JA, Wang H, Westerman R, Zeeb H, Zoeckler L, AbdAllah F, Ahmed MB, Alabed S, Alam NK, Aldhahri SF, Alem G, Alemayohu MA, Ali R, Al-Raddadi R, Amare A, Amoako Y, Artaman A, Asayesh H, Atnafu N, Awasthi A, Saleem HB, Barac A, Bedi N, Bensenor I, Berhane A, Bernabe E, Betsu B, Binagwaho A, Boneya D, Campos-Nonato I, Castaneda-Orjuela C, Catala-Lopez F, Chiang P, Chibueze C, Chitheer A, Choi JY, Cowie B, Damtew S, das Neves J, Dey S, Dharmaratne S, Dhillon P, Ding E, Driscoll T, Ekwueme D, Endries AY, Farvid M, Farzadfar F, Fernandes J, Fischer F, TT GH, Gebru A, Gopalani S, Hailu A, Horino M, Horita N, Husseini A, Huybrechts I, Inoue M, Islami F, Jakovljevic M, James S, Javanbakht M, Jee SH, Kasaeian A, Kedir MS, Khader YS, Khang YH, Kim D, Leigh J, Linn S, Lunevicius R, El Razek HMA, Malekzadeh R, Malta DC, Marcenes W, Markos D, Melaku YA, Meles KG, Mendoza W, Mengiste DT, Meretoja TJ, Miller TR, Mohammad KA, Mohammadi A, Mohammed S, Moradi-Lakeh M, Nagel G, Nand D, Le Nguyen Q, Nolte S, Ogbo FA, Oladimeji KE, Oren E, Pa M, Park EK, Pereira DM, Plass D, Qorbani M, Radfar A, Rafay A, Rahman M, Rana SM, Soreide K, Satpathy M, Sawhney M, Sepanlou SG, Shaikh MA, She J, Shiue I, Shore HR, Shrime MG, So S, Soneji S, Stathopoulou V, Stroumpoulis K, Sufiyan MB, Sykes BL, Tabares-Seisdedos R, Tadese F, Tedla BA, Tessema GA, Thakur JS, Tran BX, Ukwaja KN, Uzochukwu BSC, Vlassov VV, Weiderpass E, Wubshet Terefe M, Yebyo HG, Yimam HH, Yonemoto N, Younis MZ, Yu C, Zaidi Z, Zaki MES, Zenebe ZM, Murray CJL and Naghavi M: Global, regional, and national cancer incidence, mortality, years of life lost, years lived with disability, and disability-adjusted life-years for 32 cancer groups, 1990 to 2015: A systematic analysis for the global burden of disease study. 
JAMA Oncol 3: 524-548, 2017. PMID: 27918777. DOI: 10.1001/ jamaoncol.2016.5688

3 Sakuramoto S, Sasako M, Yamaguchi T, Kinoshita T, Fujii M, Nashimoto A, Furukawa H, Nakajima T, Ohashi Y, Imamura H, Higashino M, Yamamura Y, Kurita A and Arai K: Adjuvant chemotherapy for gastric cancer with S-1, an oral fluoropyrimidine. N Engl J Med 357: 1810-1820, 2007. PMID: 17978289. DOI: 10.1056/NEJMoa072252

4 Japanese Gastric Cancer Association: The Japanese Gastric Cancer Treatment Guidelines 2014 (version 4). Gastric Cancer 20(1): 1-19, 2017. PMID: 27342689. DOI: 10.1007/s10120-0160622-4

5 Koizumi W, Narahara H, Hara T, Takagane A, Akiya T, Takagi M, Miyashita K, Nishizaki T, Kobayashi O, Takiyama W, Toh Y, Nagaie T, Takagi S, Yamamura Y, Yanaoka K, Orita $\mathrm{H}$ and Takeuchi M: S-1 plus cisplatin versus S-1 alone for first-line treatment of advanced gastric cancer (SPIRITS trial): a phase III trial. Lancet Oncol 9: 215-221, 2008. PMID: 18282805. DOI: 10.1016/s1470-2045(08)70035-4

6 Bang YJ, Van Cutsem E, Feyereislova A, Chung HC, Shen L, Sawaki A, Lordick F, Ohtsu A, Omuro Y, Satoh T, Aprile G, Kulikov E, Hill J, Lehle M, Ruschoff $\mathrm{J}$ and Kang YK: Trastuzumab in combination with chemotherapy versus chemotherapy alone for treatment of HER2-positive advanced gastric or gastro-oesophageal junction cancer (ToGA): a phase 3, open-label, randomised controlled trial. Lancet (London, England) 376: 687-697, 2010. PMID: 20728210. DOI: 10.1016/s0140-6736(10)61121-X

7 Miyatani K, Saito H, Kono Y, Murakami Y, Kuroda H, Matsunaga T, Fukumoto Y, Osaki T, Ashida K and Fujiwara Y: Combined analysis of the pre- and postoperative neutrophillymphocyte ratio predicts the outcomes of patients with gastric cancer. Surg Today 48: 300-307, 2018. PMID: 28916967. DOI: 10.1007/s00595-017-1587-6

8 Murakami Y, Saito H, Kono Y, Shishido Y, Kuroda H, Matsunaga T, Fukumoto Y, Osaki T, Ashida K and Fujiwara Y: Combined analysis of the preoperative and postoperative prognostic nutritional index offers a precise predictor of the prognosis of patients with gastric cancer. Surg Today 48: 395403, 2018. PMID: 29027629. DOI: 10.1007/s00595-017-1599-2

9 Migita K, Matsumoto S, Wakatsuki K, Ito M, Kunishige T, Nakade H, Kitano M, Nakatani M and Sho M: The prognostic significance of inflammation-based markers in patients with recurrent gastric cancer. Surg Today 48: 282-291, 2018. PMID: 28836056. DOI: $10.1007 / \mathrm{s} 00595-017-1582-\mathrm{y}$

10 Japanese Gastric Cancer Association: Japanese classification of gastric carcinoma: 3rd English edition. Gastric Cancer 14: 101112, 2011. PMID: 21573743. DOI: 10.1007/s10120-011-0041-5

11 Bozzetti F, Bonfanti G, Morabito A, Bufalino R, Menotti V, Andreola S, Doci R and Gennari L: A multifactorial approach for the prognosis of patients with carcinoma of the stomach after curative resection. Surg Gynecol Obstet 162: 229-234, 1986. PMID: 3952614

12 Maruyama K: The most important prognostic factors for gastric cancer patients. Scand J Gastroenterol 22: 63-68, 1987. DOI: $10.3109 / 00365528709091021$

13 Sionov RV, Fridlender ZG and Granot Z: The multifaceted roles neutrophils play in the tumor microenvironment. Cancer Microenviron 8: 125-158, 2015. PMID: 24895166. DOI: $10.1007 / \mathrm{s} 12307-014-0147-5$
14 Fridlender ZG, Sun J, Kim S, Kapoor V, Cheng G, Ling L, Worthen GS and Albelda SM: Polarization of tumor-associated neutrophil phenotype by TGF-beta: "N1" versus "N2" TAN. Cancer Cell 16: 183-194, 2009. PMID: 19732719. DOI: 10.1016/j.ccr.2009.06.017

15 Sun R, Luo J, Li D, Shu Y, Luo C, Wang SS, Qin J, Zhang GM and Feng ZH: Neutrophils with protumor potential could efficiently suppress tumor growth after cytokine priming and in presence of normal NK cells. Oncotarget 5: 12621-12634, 2014. PMID: 25587026. DOI: 10.18632/oncotarget.2181

16 Ikeguchi M, Hatada T, Yamamoto M, Miyake T, Matsunaga T, Fukumoto Y, Yamada Y, Fukuda K, Saito H and Tatebe S: Serum interleukin-6 and -10 levels in patients with gastric cancer. Gastric Cancer 12: 95-100, 2009. PMID: 19562463. DOI: 10.1007/s10120-009-0509-8

17 Clark EJ, Connor S, Taylor MA, Madhavan KK, Garden OJ and Parks RW: Preoperative lymphocyte count as a prognostic factor in resected pancreatic ductal adenocarcinoma. HPB (Oxford) 9: 456460, 2007. PMID: 18345294. DOI: 10.1080/1365182 0701774891

18 Feng JF, Liu JS and Huang Y: Lymphopenia predicts poor prognosis in patients with esophageal squamous cell carcinoma. Medicine (Baltimore) 93: e257, 2014. PMID: 25501097. DOI: $10.1097 / \mathrm{md} .0000000000000257$

19 Saroha S, Uzzo RG, Plimack ER, Ruth K and Al-Saleem T: Lymphopenia is an independent predictor of inferior outcome in clear cell renal carcinoma. J Urol 189: 454-461, 2013. PMID: 23041457. DOI: 10.1016/j.juro.2012.09.166

20 Ray-Coquard I, Cropet C, Van Glabbeke M, Sebban C, Le Cesne A, Judson I, Tredan O, Verweij J, Biron P, Labidi I, Guastalla JP, Bachelot T, Perol D, Chabaud S, Hogendoorn PC, Cassier P, Dufresne A and Blay JY: Lymphopenia as a prognostic factor for overall survival in advanced carcinomas, sarcomas, and lymphomas. Cancer Res 69: 5383-5391, 2009. PMID: 19549917. DOI: $10.1158 / 0008-5472$.can-08-3845

21 Gooden MJ, de Bock GH, Leffers N, Daemen T and Nijman HW: The prognostic influence of tumour-infiltrating lymphocytes in cancer: a systematic review with meta-analysis. Br J Cancer 105: 93-103, 2011. PMID: 21629244. DOI: 10.1038/bjc.2011.189

22 Galon J, Costes A, Sanchez-Cabo F, Kirilovsky A, Mlecnik B, Lagorce-Pages C, Tosolini M, Camus M, Berger A, Wind P, Zinzindohoue F, Bruneval P, Cugnenc PH, Trajanoski Z, Fridman WH and Pages F: Type, density, and location of immune cells within human colorectal tumors predict clinical outcome. Science 313: 1960-1964, 2006. PMID: 17008531. DOI: $10.1126 /$ science.1129139

23 Tang Y, Xu X, Guo S, Zhang C, Tang Y, Tian Y, Ni B, Lu B, and Wang $\mathrm{H}$ : An increased abundance of tumor-infiltrating regulatory $\mathrm{T}$ cells is correlated with the progression and prognosis of pancreatic ductal adenocarcinoma. PLoS One 9: e91551, 2014. PMID: 24637664. DOI: 10.1371/journal.pone.0091551

24 Qiu H, Xiao-Jun W, Zhi-Wei Z, Gong C, Guo-Qiang W, Li-Yi $Z$, Yuan-Fang L and Rajiv-Prasad K: The prognostic significance of peripheral T-lymphocyte subsets and natural killer cells in patients with colorectal cancer. Hepatogastroenterology 56: 1310-1315, 2009. PMID: 19950782.

25 Tachibana T, Onodera H, Tsuruyama T, Mori A, Nagayama S, Hiai $\mathrm{H}$ and Imamura $\mathrm{M}$ : Increased intratumor Valpha24-positive natural killer T cells: a prognostic factor for primary colorectal carcinomas. Clin Cancer Res 11: 7322-7327, 2005. PMID: 16243803. DOI: 10.1158/1078-0432.ccr-05-0877 
26 Berntsson J, Nodin B, Eberhard J, Micke P and Jirstrom K: Prognostic impact of tumour-infiltrating B cells and plasma cells in colorectal cancer. Int J Cancer 139: 1129-1139, 2016. PMID: 27074317. DOI: $10.1002 /$ ijc. 30138

27 Kang YK, Boku N, Satoh T, Ryu MH, Chao Y, Kato K, Chung HC, Chen JS, Muro K, Kang WK, Yeh KH, Yoshikawa T, Oh SC, Bai LY, Tamura T, Lee KW, Hamamoto Y, Kim JG, Chin K, Oh DY, Minashi K, Cho JY, Tsuda M and Chen LT: Nivolumab in patients with advanced gastric or gastro-oesophageal junction cancer refractory to, or intolerant of, at least two previous chemotherapy regimens (ONO-4538-12, ATTRACTION-2): A randomised, double-blind, placebo-controlled, phase 3 trial. Lancet (London, England) 390: 2461-2471, 2017. PMID: 28993052. DOI: $10.1016 / \mathrm{s} 0140-6736(17) 31827-5$
28 Svaton M, Zemanova M, Skrickova J, Jakubikova L, Kolek V, Kultan J, Koubkova L, Bejckova A, Salajka F, Hrnciarik M, Melichar B, Vrana D, Konecny M, Chloupkova R and Pesek M: Chronic inflammation as a potential predictive factor of nivolumab therapy in non-small cell lung cancer. Anticancer Res 38: 6771-6782, 2018. PMID: 30504389. DOI: 10.21873/ anticanres. 13048

Received March 17, 2019 Revised March 31, 2019 Accepted April 3, 2019 